\title{
Aude Préta de Beaufort, Jean-Claude Renard, poète des noces
}

\section{Rosa Galli Pellegrini}

\section{Q OpenEdition}

1 Journals

\section{Edizione digitale}

URL: http://journals.openedition.org/studifrancesi/28068

DOI: 10.4000/studifrancesi.28068

ISSN: 2421-5856

\section{Editore}

Rosenberg \& Sellier

\section{Edizione cartacea}

Data di pubblicazione: 31 décembre 2006

Paginazione: 638

ISSN: 0039-2944

\section{Notizia bibliografica digitale}

Rosa Galli Pellegrini, « Aude Préta de Beaufort, Jean-Claude Renard, poète des noces », Studi Francesi [Online], 150 (L | III) | 2006, online dal 30 novembre 2015, consultato il 08 novembre 2020. URL : http:// journals.openedition.org/studifrancesi/28068; DOI : https://doi.org/10.4000/studifrancesi.28068

Questo documento è stato generato automaticamente il 8 novembre 2020.

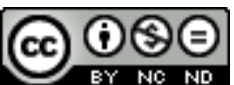

Studi Francesi è distribuita con Licenza Creative Commons Attribuzione - Non commerciale - Non opere derivate 4.0 Internazionale. 


\section{Aude Préta de Beaufort, Jean-Claude Renard, poète des noces}

Rosa Galli Pellegrini 


\section{NOTIZIA}

AUDE PRÉTA DE BEAUFORT, Jean-Claude Renard, poète des noces, Paris, Presses Univ. de la Sorbonne, 2005, pp. 278.

Il taglio scelto dall'A. in questa rielaborazione della tesi di dottorato prospetta inizialmente una lettura attenta, se non nuovissima, dell'opera di un poeta contemporaneo sulla quale la critica si è già espressa con numerose monografie e atti di convegni. Il punto di vista sul quale s'incentra analiticamente il saggio è deducibile dal titolo stesso: "nozze", interpretate come "unione" ( o eventuale "divorzio") di categorie spirituali, viste spesso, nella cultura occidentale, come antitetiche. La studiosa presenta la sua ricerca seguendo un percorso che, nell'opera come nella vita di Jean-Claude Renard, parte da esperienze personali, comunque correlate al contesto letterario storico nel quale il poeta, nato nel primo dopoguerra e scomparso nel 2002, si trova a scrivere. Pertanto, la lettura critica prende in considerazione, in primo luogo, le opere giovanili, "nozze di carne", per continuare con quelle composte durante un breve approccio all'esoterismo che risentono di una fascino dell'occulto e dell'ermetico. Impregnato dell'eredità cattolica in cui cresce, il poeta se ne discosta tuttavia, coniugando misticismo e mistero in un'alleanza superiore. La seconda parte del saggio risulta più tecnico, in quanto attento alla struttura e al linguaggio poetico, nonché alla poetica stessa di Renard. La terza parte, infine, sicuramente la più originale, affronta il nocciolo della questione critica, mettendo in luce lo sforzo del poeta per unificare la realtà vissuta con una presenza altra, che gravita nella sfera dello spirituale senza peraltro rientrare nel fideismo di matrice religiosa.

Una esauriente bibliografia arricchisce il pregevole lavoro critico. 